\title{
Teoria social e desafios epistemológicos na geopolítica do conhecimento
}

\section{Social theory and epistemological challenges in the geopolitics of knowledge}

\author{
Lucas Amaral de Oliveira*
}

Resumo: Inflexões epistemológicas importantes têm emergido em contextos acadêmicos periféricos e semiperiféricos de produção de saberes, tensionando noções já consolidadas nas Ciências Sociais de "modernidade" e "razão científica”. Esses deslocamentos afetaram a Teoria Social, primeiro, no universo indiano e anglo-saxão e, em um segundo momento, na América Latina, quando se passou a problematizar de forma mais aguda o lado atroz da modernidade, a partir de uma releitura de realidades que experimentaram colonização, escravismo, etnocídio, sexismo e racismo. Este artigo compõe uma revisão analítica e panorâmica da maneira como parte da Teoria Social Contemporânea tem buscado desconstruir a ideia de uma "experiência moderna" monotópica e universal, e de como essa desconstrução tem alargado cada vez mais nossos horizontes de entendimento sobre subalternidades e colonialidades. O objetivo é expor críticas a respeito da produção, difusão e consumo de "grandes narrativas”, articulando tais propostas com abordagens recentes que propõem o reexame de cânones firmados na Sociologia e indicando novas epistemologias a partir de outros locais de enunciação, fala e atuação.

Palavras-chave: Teoria Social. Colonialidades. Epistemologias Decoloniais.

Abstract: Significant epistemological turns have emerged in peripheral contexts of knowledge production, tensioning consolidated notions of "modernity" and "scientific reason". These turns have largely affected Social Theory, at first in the Indian and Anglo-Saxon academic universe, and hereafter in Latin America, when a critical re-reading of realities that have experienced colonization, slavery, ethnocide, sexism, and racism began to problematize the "dark side of modernity". This article intends to analyze how Contemporary

\footnotetext{
* Professor Adjunto do Departamento de Sociologia da Universidade Federal da Bahia e Coordenador do "Periféricas - Núcleo de Estudos em Teorias Sociais, Modernidades e Colonialidades".
} 
Social Theory has deconstructed the idea of a monotopic, universal, and absolute modernity, and how this has broadened our horizon of understanding on subalternities and colonialities. The aim is to present criticisms regarding the production, circulation, and consumption of great narratives, by articulating such proposals with approaches that are suggesting a review of the well-known canons in Sociology, in order to indicate new epistemologies from other places of enunciation, talk, and agency.

Keywords: Social Theory. Colonialities. Decolonial Epistemologies.

\begin{abstract}
"Talvez a tarefa mais importante seja a de empreender estudos de alternativas contemporâneas ao orientalismo, e perguntar como é possível estudar outras culturas e povos a partir de uma perspectiva libertária, ou não repressiva e não manipulativa". Edward W. Said, Orientalismo, 1978.
\end{abstract}

\title{
I
}

Nos cursos de Ciências Sociais, no Brasil, ainda se nota tendências à identificação da "grande teoria" (política, sociológica, antropológica) com um conjunto de saberes, abordagens, técnicas e métodos produzido na "EuroAmérica" - para usar o termo de Jean e John Comaroff (2013). Segundo argumenta Raewyn Connell (2007), se deslocarmos esse fato para um contexto internacional de produção de conhecimento sociológico, perceberemos uma divisão global do trabalho acadêmico inscrita sob a égide de uma geopolítica científica historicamente desigual: afinal, é do Norte Global que teorias com pretensões explicativas universalistas são importadas, o que acirra processos de dependência epistêmica (ALATAS, 200o); ao passo que, ao restante, concede-se o epíteto de "teorias locais" semiautônomas - como Sociologia Brasileira (ou, o que é mais sintomático nesse processo, Pensamento Social Brasileiro), Colombiana, Sul-Africana, Chinesa, etc. -, cuja alcance analítico não logra ultrapassar suas respectivas fronteiras regionais.

Isso nos leva a duas constatações e a uma tarefa inadiável: 1) há inequívocas relações de poder enraizadas nas dinâmicas globais de produção de "saberes legítimos" entre Norte e Sul Global, 2) o que aponta para desigualdades na divisão internacional do trabalho acadêmico (ALATAS, 2003; CONNELL ET 
AL., 2018; KEIM, 2008; MEDINA, 2013); em virtude dessas dinâmicas diferenciadas, nossa tarefa mais urgente é desmontar o "eurocentrismo teórico" (HOSTETTLER, 2008), o "colonialismo acadêmico" (CONNELL, 2015; GROSFOGUEL, 2007B; MIGNOLO 1993) e o "imperialismo intelectual" (ALATAS; SINHA, 2017; GO, 2016) dos centros de produção científica, a fim de equalizar as oportunidades e os espaços de produção do conhecimento sociológico.

No limite, o Sul Global ainda consome repertórios teórico-metodológicos procedentes de fora, sintetizados em um saber instantaneamente universalizável, quase sempre a partir de dados empíricos e da matéria bruta concebida e colhida localmente. Esse processo assimétrico foi corretamente esboçado por Syed F. Alatas (2003; 2010) como efeito de uma "dependência acadêmica", decorrente de "episteme imperial" (GANDHI, 1998; GO, 2016; SAID, 1990) ainda vigente nas Ciências Sociais do mundo inteiro, fenômenos que, se combinados com os já bem-sucedidos projetos de dominação política, econômica e cultural, conformam o que Mignolo (2003) chama "geopolítica do conhecimento", que induz uma série de violências epistêmicas.

Poderíamos acrescentar que se trata de mais uma variante daqueles processos que Sueli Carneiro (2005) e Boaventura de Sousa Santos (1994) acusam de "epistemicídio", na medida em que se percebe a conexão entre violências epistêmicas globais e a invenção de um Outro descorporificado, descontextualizado, exotizado, essencializado (indígena, escravizado, mulher, homossexual, migrante, etc.). O homem branco, capitalista, europeu, cristão, cis e heterossexual trouxe consigo, para as Américas, um saber que acompanhou o mesmo padrão hierárquico na produção e reprodução da "colonialidade do saber" (LANDER, 2005), cúmplice do sexismo, racismo, orientalismo ${ }^{1}$, universalismo e objetivismo. Ramón Grosfoguel (2007a) ratifica tal diagnóstico,

\footnotetext{
${ }^{1}$ Para Said (1990), a modernidade ocidental generalizou as diferenças entre diversas culturas, homogeneizando-as e inferiorizando-as, ora sob uma caricatura exótica, ora como estereótipo representativo do mal absoluto - a "demontologia imaginativa" e a obliteração do "oriental" como pessoa. Essa imagem não corresponde à realidade, mas à representação culturalmente construída pelas metrópoles dos povos sob seu domínio. Logo, o Orientalismo é o imperialismo a nível cultural: um corpo de teorias e práticas a partir do qual, por gerações, investimentos foram feitos em uma ideia estereotipada de Oriente. Já que o Ocidente detém autoridade intelectual de estabelecer regimes e efeitos de verdade, cria-se uma tensão sintomática: "razão", "técnica", "ciência" e "progresso" são marcas da modernidade ocidental, enquanto o Oriente liga-se ao "misticismo", ao "paganismo", à "desrazão" e ao "natural”.
} 
salientando que, nas teorias ocidentais, o sujeito da enunciação está escondido, apagado das análises. A esse ocultamento, o sociólogo porto-riquenho denomina "ego-política do conhecimento legítimo", que acaba privilegiando o mito de um sujeito da razão não situado. A posição epistêmica e o lugar social/étnicoracial/sexual/de gênero desse sujeito hegemônico e intocável se acham desvinculados; com efeito, se nos aparece uma razão científica na qual o sujeito cognoscente não possui sexualidade, gênero, etnia, raça, classe, corte geracional, espiritualidade, língua, localização epistêmica e geográfica, não exercendo qualquer relação de poder e, com efeito, produzindo regimes e efeitos de verdade desde um monólogo consigo mesmo, sem relação com ninguém fora de si (BELLESTRIN, 2013; GROSFOGUEL, 2007a).

Esse debate conduz à problemática sobre como entendemos a questão do universalismo dentro na Teoria Social. É razoável pensar que teorias criadas localmente - isto é, em poucas cidades europeias -, com base em experiências de uma pequena porção da humanidade do Norte Global, sejam estendíveis para todos os lugares, a nível mundial? Tal questão foi colocada por Marcelo Rosa (2015), e ela soa mais pungente quando lidamos com o dilema da "modernidade". Segundo a equação de Boaventura de Sousa Santos (2007), a "modernidade monotópica" do Norte Global não se deu ao esforço de reconhecer a coexistência de várias modernidades locais, plurais e interconectadas (BHAMBHA, 2014), de modo que rotulou como primitivas, obsoletas, pré-modernas, selvagens, atrasadas, residuais as experiências divergentes e alternativas àquelas ditadas pela modernidade euro-norteamericana - que hierarquizou pessoas, povos, práticas, cosmologias, línguas, corpos, habitus e saberes, impondo um caráter natural a tal classificação.

No entanto, nas últimas décadas, têm surgido um conjunto heterogêneo de movimentos epistemológicos em contextos periféricos e semiperiféricos de produção acadêmica que têm se mostrado persistente em tensionar as concepções mais consolidadas de "modernidade" e de "razão científica". Ainda que nomes como Edward Said, Aimé Césaire, Albert Memmi, Frantz Fanon, Amílcar Cabral, W.E.B. Du Bois, C.L.R. James e tantos/as outros/as despontem como pioneiros/as do debate pós-colonial (ALMEIDA, MIGLIEVICH-RIBEIRO; GO, 2016; GOMES, 2013; YOUNG, 2011), esses movimentos oriundos de 
diversas áreas disciplinares afetaram a Teoria Social sobremaneira: primeiro, no universo indiano e anglo-saxão, com os Estudos Subalternos; em seguida, na América Latina, com os chamados Estudos Decoloniais. Este, especificamente, passou a problematizar o lado atroz e perverso da modernidade a partir do reconhecimento e do exame de realidades históricas locais que foram marcadas, em seus respectivos processos de formação nacional, por colonização, escravismo, etnocídio, sexismo, supremacia branca² ${ }^{2}$ etc.

Este artigo, motivado por uma problemática que tem a Sociologia como destino teórica-metodológico, pretende realizar uma análise panorâmica do modo como, nas últimas décadas, se tem tentado desconstruir a ideia de uma modernidade monotópica, universal e absoluta na Teoria Social, e como essa tentativa tem alargado nosso horizonte de entendimento sobre a produção de subalternidades e colonialidades de distintos alcances. Assim, gostaria de expor uma revisão das principais críticas erigidas sobre a produção, circulação e consumo de "grandes teorias" importadas do Norte Global, articular essas propostas científicas com aportes mais contemporâneos que têm tentado reinterpretar cânones já estabelecidos na Teoria Social e, enfim, indicar epistemologias alternativas a partir de outros locais de enunciação, fala e atuação.

\section{II}

Há ao menos duas acepções para o termo "pós-colonial". A primeira seria uma condição histórico-política que remete ao período posterior aos processos "tardios" de descolonização em países do "Terceiro Mundo" - entre 1950 e 197033 (BALLESTRIN，2013; CHAKRABARTY，2000a; MENESES, 2016;

\footnotetext{
2 Para bell hooks (1984), o termo "supremacia branca" é preferível a "racismo", porque este tende a manter pessoas brancas no centro das discussões e não viabilizar o discurso da colonização/descolonização, impedindo que facetas psicológicas e epistemológicas do preconceito de cor eclodam. hooks se aproxima do debate decolonial quando argumenta que a "supremacia branca" não envolve pessoas brancas em termos individuais ou coletivos, mas sim as discussões sobre patriarcado e capitalismo, tomando essa supremacia como um sistema institucional mais amplo que atua a nível global e estrutura nossas formas de pensar, agir, interagir e performatizar identidades políticas.

$3 \mathrm{O}$ contexto dessa emergência foi marcado por uma avalanche de discursos anticoloniais e antirracistas no Sul Global, mas também, a um nível internacional, pela Guerra do Vietnã e da Coreia, pelos conflitos árabe-israelenses, pelas Ditaduras na América Latina, pelas políticas segregacionistas na África do Sul e nos EUA, pelos Movimentos de Libertação Nacional africanos e pela Guerra Fria e a divisão dual do mundo entre capitalistas e socialistas.
} 
YOUNG, 2001). As guerras de libertação em África e Ásia, somadas à diáspora intelectual, à experiência dos trânsitos internacionais entre metrópole e colônia e à dilatação das fronteiras nacionais provocadas pelas relações coloniais fizeram nascer uma rede de crítica intelectual nas periferias e semiperiferias do capitalismo (MIGLIEVICH-RIBEIRO, 2014). O fenômeno da diáspora acarretou outros lugares de enunciação, o que Mignolo (2003) intitulou "pensamento fronteiriço" ou "gnose limiar", a partir de onde se tencionou leituras canônicas e se ampliou vozes silenciadas e desautorizadas epistemicamente (ALCOFF, 2016; SITAS, 2006).

Isso conduz à segunda acepção do "pós-colonial": um conjunto de contribuições teórico-metodológicas e epistemológicas que surgiram, na historiografia crítica e nos estudos culturais, a partir da década de 1970, com forte repercussão na Índia, nos Estados Unidos e na Inglaterra. O objetivo dessas abordagens foi produzir um saber desvinculado do eurocentrismo, ainda que por vezes flertando com correntes europeias, como o pós-estruturalismo e o marxismo. Os grandes nomes dos Postcolonial Studies são Frantz Fanon, Cheikh Diop, Albert Memmi, Aimé Césaire, Edward Said, Amílcar Cabral, Kwame Nkrumah, Ngũgĩ wa Thiong'o e Anita Desai (Ashcroft et al., 2002), aos quais se seguiram, a partir da década de 1980, Gayatri Spivak, Partha Chatterjee, Dipesh Chakrabarty, Gyanendra Pandey e Ranajit Guha4, sob os auspícios de uma corrente que ficou conhecida como Subaltern Studies - que se tornaram, depois, como lembram Homi Bhabha (2001) e Vinayak Chatuverdi (2000), um campo de especialização acadêmica.

Chakrabarty (200ob) atenta para o fato de que, sob influências diversas de Antonio Gramsci a Michel Foucault e Gilles Deleuze, de Jacques Derrida a Frantz Fanon e Edward Said -, em 1982, a série Subaltern Studies: Writings on Indian History and Society começou publicando intervenções de intelectuais sobre debates específicos acerca da escrita da "moderna história indiana"; nos anos seguintes, os Estudos Subalternos passaram a designar um campo acadêmico e disciplinar frequentemente aceito como desdobramento do

\footnotetext{
4 Ballestrin (2013) lembra que o grupo nasceu sob a liderança de Ranajit Guha, dissidente do marxismo indiano, cujo projeto era reavaliar não só a historiografia colonial da Índia feita por ocidentais europeus, mas também a historiografia eurocêntrica nacionalista indiana, bem como a historiografia marxista ortodoxa feita em seu país.
} 
pensamento pós-colonial, muitas vezes se confundindo com ele, apesar da heterogeneidade nas produções.

Alguma dessas contribuições se centraram em interrogar os regimes e efeitos de verdade da própria escrita da história, mostrando que essa escrita, como ato discursivo de produção e reprodução de "fatos", está rigorosamente ligada às relações de poder e a campos discursivos específicos, que poderão produzir diferenças epistêmicas sobre o sentido e a "verdade" dos enunciados. Spivak (1988), em especial, irá criticar o fato de a historiografia eurocêntrica "falar pelos outros" de modo vertical, algo chancelado pelo paradigma da ciência moderna, na medida em que tal atitude envolveria processos perigosos de representação simbólica, sobretudo para comunidades marginalizadas que historicamente estão fadadas a serem mal compreendidas ou, então, equivocadamente representadas por conveniência e interesse de quem detém poder e meios para representá-las (ALCOFF, 1991; SPIVAK, 1988; BAHRI, 2013; OLIVEIRA, 2018; 2020).

Contudo, ao mesmo tempo, Spivak (1988) irá rejeitar o retraimento total de "falar pelos outros", criticando atitudes de quem ela acusa de serem "intelectuais abnegativos". A teórica indiana se refere às posições de abnegação que, nos anos 1960, figuras como Foucault e Deleuze adotaram no debate público francês usando a justificativa de que os "oprimidos", se quisessem, poderiam representar de forma transparente seus interesses e expressar de maneira livre suas demandas políticas. Foucault e Deleuze (1977) arquitetam essa discussão sobre a "função social do intelectual" a fim de desconstruir a figura do "intelectual total", que insiste em "falar pelos outros" - "em nome dos outros" e/ou "no lugar dos outros". Para eles, o intelectual não poderia mais representar os oprimidos, mas sim gerar condições para que eles falem por si próprios.

Essa conversa acaba sendo um dos gatilhos de Spivak (1988), em seu ensaio "Pode o subalterno falar? Especulações sobre o sacrifício das viúvas", de 1985, onde ela acusa os filósofos franceses de não conseguirem tensionar seu próprio lugar de enunciação - o do sujeito que ocupa posição epistemológica e simbólica de poder e privilégio, inclusive na narração da história. Não logram pensar seu lugar de enunciação pois ainda detêm o poder de instituir o "outro" 
da fala, de apontá-lo com os dedos, com a peculiaridade de reconhecer que esse "outro", enquanto subalterno, deve agora falar por si próprio - afinal, supostamente, ele não precisaria mais de mediadores e representantes para contar a própria história. Para Spivak, o intelectual ocidental (homem-brancoeuropeu) - oscilando entre prepotência e condescendência -, apesar de abnegativo em pretensões representativas e indulgente no discurso em relação aos "outros", seguiria transcendente no desejo de nomear, classificar, delegar funções e prescrever medidas, porque deteria a "autoridade" de dizer quem são os "outros", os subalternos, proclamando que seus discursos são significativos e merecem ser articulados pelos próprios oprimidos.

A saída de Spivak (1988) é sugerir que o/a "narrador/a da história" não negue seu papel descritivo e analítico, que não se abstenha de certa dose de abertura etnográfica se necessário, mas que tampouco presuma, na escrita/fala, uma autenticidade essencialista e romântica dos/as mais oprimidos/as na constituição de suas narrativas e de sua autorrepresentação. Ao contrário, é preciso que se admita, no processo de produção de um saber crítico e público, a possibilidade de que agentes e grupos que ocupam posições marginalizadas de desvantagem - que não detêm acesso integral às mesmas marcas distintivas, aos meios de produção simbólica, ao poder de estabelecer as condições de possibilidade de suas histórias - produzam narrativas, réplicas, críticas e enunciados que possam ser postos em um sistema de relações dialógicas e reflexivas.

Sérgio Costa (2006b) afirma que, a despeito das dessemelhanças teóricas que separam autores/as tão díspares como Fanon, Said, Guha, Bhabha e Spivak, que se mostraram seminais para a Teoria Social na segunda metade do século $\mathrm{XX}$, é preciso dizer que eles/as tiveram uma agenda intelectual: romper com a tirania da história (e da Teoria Social) única, sustentada por metanarrativas ocidentais; superar ideologias de progresso e modernização singulares; elaborar críticas às matrizes de dominação colonial e aos "processos civilizatórios" etnocêntricos; e desconstruir os essencialismos assentados em classe, raça, etnia, nação e gênero. Nesse sentido, as perspectivas pós-coloniais, apesar de sua heterogeneidade, buscaram construir análises culturais sem dispensar a economia política, além de elaborar diagnósticos macro históricos sem ignorar 
as especificidades locais, aliando métodos comparativos e etnográficos. Para tanto, lograram reverter algumas compreensões globalizantes da Teoria Social ao substituí-las (ou, melhor, ao complementá-las) por perspectivas subalternizadas. E, ao fazê-lo, deslocaram a ação da mudança social na figura do subalterno, politicamente oprimida, economicamente explorada, culturalmente emudecida e contra a qual pesam várias matrizes de discriminação (Guha, 2002).

Stuart Hall (1996), ao designar a "diferença específica" do pensamento pós-colonial em relação à historiografia e à teoria crítica marxistas, afirmou que o movimento como um todo constituiu um conjunto de engajamentos teóricos e políticos de "pensar nos limites" da Teoria Social forjada no Ocidente. Para ele, nada nos impediria de ler o "pós-colonial" de modo mais ortodoxo, como movimento anti-imperialista e descentralizador construído a partir do "Terceiro Mundo". O historiador turco Arif Dirlik (1996, p. 302) ecoa essa leitura ortodoxa, quando diz que as inovações historiográficas trazidas pelos Subaltern Studies nada mais são que aplicações de métodos pioneiros dos marxistas britânicos, como E.P. Thompson e Eric Hobsbawm, mesmo que transformados pelas "sensibilidades terceiro-mundistas". Porém, não se trata só disso. O sociólogo jamaicano nota que muitos/as não conseguiram captar o vanguardismo do fenômeno pós-colonial porque ficam presos apenas ao sentido político do mesmo. Com isso, Hall (1996, p. 254) realça a perspectiva da mudança estrutural presente no quadro de referência das teorias pós-coloniais, no mais alto nível de abstração intelectual, na medida em que esse conjunto de aportes elaborou uma inflexão radical à episteme imperial, para interromper a falsa distinção entre colonialismo como sistema de governança e colonialismo como sistema de conhecimento, classificação e representação. Isso permitiu, de um lado, que o fenômeno fosse relido desde as experiências reais de povos subalternizados (GO, 2013); de outro, que vozes/agências adquirissem abrangência e dilemas das "sociedades pós-coloniais" fossem mais bem traçados. 
No início dos anos 1990, uma extensão desse movimento se firmou na América Latina, quando intelectuais das Ciências Sociais passaram a radicalizar críticas ao "metrocentrismo"5 epistemológico e aos resquícios do colonialismo ibérico, a partir das especificidades locais do continente, revelando relações de poder embutidas nas dinâmicas globais de produção do saber.

Luciana Ballestrin (2013) remonta bem a história dessa mudança paradigmática que foi levada à cabo, primeiro, pelo Grupo Latino-Americano de Estudos Subalternos e, em seguida, pelo Grupo Modernidade/Colonialidade, ambos compostos por intelectuais de várias universidades das Américas. Os dois grupos de pesquisa, orquestrando a nível local algumas das inquietações do grupo indiano (Subaltern Studies Collective), tiveram influência do Marxismo Latino-Americano, das Teorias da Dependência, da Filosofia da Libertação, do Pós-Estruturalismo, além dos próprios Estudos Subalternos. Muitos/as deles/as, alocados em instituições estadunidense, como Edgardo Lander, Linda Alcoff, Arturo Escobar, Walter Mignolo, Enrique Dussel, Aníbal Quijano, Catherine Walsh, Iliana Rodriguez, Fernando Coronil e María Lugones, constituem, ainda hoje, nomes que despontam quando falamos de "colonialidade" e "decolonialidade" (BALLESTRIN, 2013; MIGLIEVICHRIBEIRO; PRAZERES, 2015).

A ideia que atravessava ambos os projetos era a de realizar um movimento de renovação crítica/utópica das Ciências Sociais (BALLESTRIN, 2013; GROSFOGUEL, 2002), radicalizando o argumento pós-colonial por meio daquilo que Nelson Maldonado-Torres (2011) denominou "giro decolonial" sem o "s", para distinguir o projeto intelectual da ideia histórica de "descolonização" via libertação nacional durante a Guerra Fria ${ }^{6}$. Os/as

\footnotetext{
5 "Metrocentrismo" é um conceito trabalhado por Julian Go para referir-se à justaposição de três fatos históricos: Orientalismo, universalismo eurocêntrico e repressão da história do imperialismo/colonialismo, sobretudo dentro da Teoria Social do Norte Global. Para ele, "metrocentrismo" constitui um dos principais alicerces da consolidação e institucionalização da Sociologia como disciplina fundamentalmente moderna na Europa ocidental (Go, 2016).

6 Nelson Maldonado-Torres foi quem coordenou uma conferência, em 2005, em Berkeley, intitulada Mapping Decolonial Turn, que consolidou a ideia de um giro epistemológico na América Latina e ajudou a constituir a "decolonialidade" como o terceiro elemento da relação modernidade/colonialidade, como espaço onde o próprio pensamento foi negado pelo império da modernidade europeia (Ballestrin, 2013; Miglievich-Ribeiro, 2014). É por isso que Dussel (2002) defende a transmodernidade como um projeto de liberação intelectual, política, econômica, linguística, ecológica, pedagógica e religiosa, que rompa com a lógica da "modernidade" - redutora de identidades, produtora de subalternidades. A transmodernidade opõe-se à gnose totalizante, prezando a pluriversalidade como demanda global. Como diz
} 
teóricos/as defenderam a "opção decolonial" nas periferias e semiperiferias do capitalismo, a fim de entender e atuar em um mundo marcado pela colonialidade de variados graus e alcances. Dois escritos essenciais demarcaram a inserção do continente no debate pós/decolonial: "Colonialidad y modernidad-racionalidad”, de Aníbal Quijano (1992), e Manifiesto Inaugural del Grupo Latinoamericano de Estudios Subalternos (1993), inicialmente publicado em inglês como Founding Statement.

O Grupo Modernidade/Colonialidade data do final da década de 1990, quando o Grupo Latino-Americano de Estudos Subalternos se fragmentou. As críticas que levaram à cisão eram de que o primeiro grupo espelhava os métodos do Grupo Sul-Asiático de Estudos Subalternos e, portanto, não esquadrinhava uma ruptura filosófica radical com as epistemes do Norte Global, sobretudo em relação a Michel Foucault, Jacques Derrida e Antonio Gramsci, suas maiores influências (BALLESTRIN, 2013; MIGLIEVICH-RIBEIRO, 2014; VERDESIO, 2005). Em razão dessas dissidências, o grupo se decompôs em meados de 1998, e alguns desses intelectuais começaram a se reunir para criar o "Modernidade/Colonialidade". Tal grupo foi sendo edificado através de seminários, fóruns, debates e publicações conjuntas, achando espaço de interlocução na CLACSO - Conselho Latino-Americano de Ciências Sociais7 (BALLESTRIN, 2013). Em 2000, foi lançado a obra La colonialidad del saber, editada pelo sociólogo venezuelano Edgardo Lander (2005), como produto colaborativo do Simpósio "Alternativas al Eurocentrismo y Colonialismo en el Pensamiento Social Latinoamericano Contemporáneo", organizado no Congresso Internacional de Sociologia da ISA de 1998, realizado em Montreal. O livro conferiu agendas programáticas ao grupo, sobretudo por questionar legados coloniais/eurocêntricos dos saberes sociais sobre o continente, expressos no regime de diferenciação que lhes servem de alicerce

Mignolo (2006, p. 677), o futuro não pode ser imaginado como "movimento na direção da completude do projeto incompleto da modernidade", mas como um mundo para o qual todas as racionalidades possam contribuir transversalmente: "A socialização do conhecimento, a superação do totalitarismo epistêmico, implica a superação da modernidade/colonialidade [...]; o 'mito da modernidade' justificou não só o totalitarismo científico, mas o totalitarismo tout court, como o estamos a testemunhar no início do século XXI à escala global".

7 Embora não diretamente filiados ao movimento, Lewis Gordon, Orlando Fals Borda, Pablo Gonzáles Casanova, Immanuel Wallerstein, Maria Paula Meneses e Boaventura de Sousa Santos, entre outros/as são intelectuais que buscaram manter debates prolongados com o grupo (Ballestrin, 2013; Miglievich-Ribeiro, 2014; Santos, 2019). 
epistemológico e na própria ideia de "modernidade" como modelo civilizatório universal.

O objetivo do Modernidade/Colonialidade era o tensionar os modelos e repertórios explicativos, os métodos de investigação e as categorias analíticas da Teoria Social do fim do século XX e início do XXI. A crítica aos diversos modos de opressão interseccionados e a articulação histórica do "inacabado projeto da modernidade" (HABERMAS, 1992) com a noção de "colonialidade do poder" (QUIJANO, 1992), depois dilatada para as colonialidades do saber e do ser (MALDONADO-TORRES, 2007; 2008; LANDER, 2005), possibilitou a renovação das Ciências Sociais no continente (BALLESTRIN, 2013). Em decorrência desse deslocamento epistemológico, passou-se a questionar o lugar de enunciação de sujeitos abstratos (Ciência, Estado, Homem), lugares onde se assentava a "ideia-tabu" de objetividade, universalidade e neutralidade do sujeito da razão científica. Intelectuais engajados no debate, como Dussel (2002; 2005), Walsh (2009), Anzaldúa (1987), Castro-Gómez (2017), CastroGómez e Grosfoguel (2007), Lugones (2014) e Segato (2018) historicizam o processo de institucionalização dessa episteme imperial, afirmando que o sujeito do conhecimento científico sempre foi situado, social e historicamente.

No que se refere à designação do grupo, os dois termos que compõem a díade que, hoje, também sintetiza um esquema analítico de diagnose do Ocidente, modernidade e colonialidade, se lidos separadamente, podem ser tratados através de vários prismas. Juntos, entretanto, adquirem correspondência graças a uma asserção, marcada pela barra que os separa: a constituição histórica da ideia de modernidade ocultou sua colonialidade, cuja análise abre janela de crítica sobre o lado atroz e sombrio dessa modernidade. Isso leva a pensar, por um lado, que nunca houve modernidade sem colonialidade; de outro, que essa mesma modernidade fundada na matriz ocidental da racionalidade científica e das segmentações do metrocentrismo sempre foi totalitária, na medida em que depreciou vivências outras e saberes situados fora do eixo "euro-norte-americano". Nesse sentido, a própria ideia de colonialidade, um neologismo acadêmico transformado em categoria sociológica por Aníbal Quijano (1992), faz referência a estrutura de poder específica do domínio colonial moderno à qual foram submetidos os povos originários a 
partir de 1492 - e que ainda persistem após as independências na América Latina.

A inspiração para a elaboração do conceito vem da obra do escritor e filósofo peruano José Carlos Mariátegui, com quem Quijano tem uma relação de profunda admiração e afinidade (RUBBO, 2018), sobretudo no que se refere à sua "utopia indigenista", a partir da qual Mariátegui (2010) construiu elos analíticos entre raça, terra e colonialismo. A distinção entre colonialidade e colonialismo permite explicar a persistência das formas coloniais de poder e dominação, além de demonstrar que tais estruturas passaram a ser reproduzidas pelos mecanismos do sistema-mundo capitalista moderno. Classificação e hierarquização são, então, motes epistêmicos na produção da "colonialidade do poder". Se, de um lado, o conceito de Quijano mostrou que as relações de colonialidade não desapareceram com a desintegração do colonialismo histórico (QUIJANO, 1989), por outro, o próprio colonialismo, enquanto sistema de conquista, dominação, diferenciação e "aculturação", acarretou as colonialidades presentes no cotidiano de povos subalternizados. Essa presença se firmou porque haveria uma continuação das formas de dominação produzidas pelas atuais estruturas do sistema-mundo capitalista, que impõem uma divisão internacional do trabalho com hierarquias complexas e níveis entrelaçados de dominação social, econômica, étnico-racial e de gênero (QUIJANO, 1992; 2014; WALLERSTEIN, 2007). Colonialidade, portanto, é o lado perverso da modernidade, mas também sua face indissociavelmente constitutiva, na medida em que ela se acha acoplada à própria experiência colonial (QUIJANO, 2010; BALLESTRIN, 2013; 2017; SEGATO, 2018).

Mignolo, em Historias locales/diseños globales (2003), argumenta que as perspectivas decoloniais, se lidas como correntes contra hegemônicas de pensamento, permitiram que se identificasse a construção da "diferença colonial" na América Latina - invenção imperialista que separa, classifica, nivela e submete corpos, saberes e memórias por meio de processos de racialização. Para o argentino, na "barra" que une e separa "Modernidade/Colonialidade", se estabelece a própria diferença colonial; não mais a diferença sociocultural, mas a transformação dessa diferença em valores e hierarquias: raciais e patriarcais, de um lado, geopolíticas e epistemológicas, 
de outro. Logo, noções como "Novo Mundo", "Terceiro Mundo", "Países Subdesenvolvidos", "Periferias do Capitalismo", etc., seriam classificações epistêmicas, sendo que quem classifica controla o saber (MIGNOLO, 2003; 2006). A diferença colonial também constituiu uma técnica para rebaixar populações e regiões do globo; ao transformar alteridades em valores mercantis, ela fez com que a América Latina passasse a ser não só diversa da Europa, mas zona ontologicamente inferior, com seus povos, línguas, tradições, práticas e cosmologias.

Não há modernidade sem colonialidade. Todavia, a colonialidade não deve ser vista só em sua dimensão do poder. Enrique Dussel (2005) argumenta que, no singular, a modernidade seria um mito a ocultar uma série de colonialidades atuantes no mundo: do poder, do saber, do ser, do gênero, etc. E assim o faz do seguinte modo: a Europa se vê como superior ao resto do mundo; essa conjecturada superioridade a obriga a desenvolver os "atrasados", seguindo o imperativo categórico do progresso; o caminho desse "processo civilizador" é o trilhado pela Europa; contudo, como o "atrasado" se opõe à civilização, é preciso exercer uma violência ética necessária para pulverizar os obstáculos de sua própria modernização; essa violência produz vítimas irremediáveis (genocídio, escravidão, estupro, destruição ecológica, epistemicídio); para o europeu moderno, o "atrasado" carregaria, portanto, uma culpa por se insurgir contra esse processo civilizador; a expiação dessa culpa faz com que a modernidade se apresente como "emancipadora" de suas vítimas e catalizadora para os colonizadores; finalizando o ciclo dessa lógica feroz, em razão do caráter "civilizador" da modernidade, consideram-se inevitáveis os sofrimentos da modernização de outros povos, nada mais que efeitos colaterais do bem maior.

\section{IV}

Opondo-se a enfoques que decodificaram a "experiência moderna" como epifenômeno puramente europeu, nos últimos anos, têm emergido discursos alternativos: "modernidades múltiplas", de Shmuel Eisenstadt (2002) e Gurminder Bhambra (2007), "modernidades alternativas", de Dilip Gaonkar (1999), "muitas modernidades", de Björn Wittrock (2000), "modernidades periféricas", de Beatriz Sarlo (2010), "variedade de modernidade", de Volker 
Schmidt (2006), "modernidades globais", de Arif Dirlik (2003), "terceira fase da modernidade”, de José Maurício Domingues (2011), "modernidade seletiva”, de Jessé Souza (2000), "modernidades entrelaçadas", de Shalini Randeria (2010) e Göran Therborn (2003), "transmodernidade”, de Enrique Dussel (2002), só para citar os movimentos mais comentados na Sociologia Global. Ao lado dessas abordagens descentralizantes, Alatas e Sinha (2017) notam o advento de epistemologias sociológicas cunhadas a partir da afirmação do Sul como local de criação e enunciação, empenhadas em tensionar as implicações de fenômenos como o orientalismo, o metrocentrismo, o colonialismo, o eurocentrismo, o androcentrismo e o racismo estrutural nas dinâmicas produtivas de "saberes legítimos". Tais leituras criticam, desconstroem e suplantam alicerces totalizantes que ainda guiam a Sociologia, pondo-se em contraste a discursos hegemônicos e reconhecendo experiências históricas que não só as do Norte Global.

Ainda que a Sociologia, quando comparada a outras áreas das Humanidades, tenha se mostrado vagarosa em envolver-se com os programas teórico-metodológicos e epistemológicos dos aportes pós e decoloniais (ADAMS ET AL., 2005; BHAMBRA, 2010; COSTA, 2006a; GO, 2013; GO, 2016; HANAFI, 2020; MCLENNAN, 2003; SITAS, 2006), como fez com a Teoria Crítica no pós-guerra, a disciplina tem dado sinais de revigoramento quando essas contribuições são mobilizadas para colocar em xeque padrões metrocêntricos de produção do conhecimento, seja desmontando metanarrativas originárias (CONNELL, 2007; ALATAS; SINHA, 2017; STEINMETZ, 2013), seja dilatando fronteiras epistêmicas (PATEL, 2014; KEMPEL; MAWANI, 2009).

De um lado, seria possível afirmar que as teorias pós e decoloniais avançaram críticas importantes a respeito dos processos que fundamentaram a institucionalização da Sociologia, o que implica reconhecer que a disciplina se firmou como um tipo de racionalização científica da "modernidade europeia" durante o auge do imperialismo/colonialismo. De outro, é preciso dizer que a valorização e a intersecção de "sociologias" de diferentes partes do mundo podem não apenas mostrar a profunda desigualdade na geopolítica do 
conhecimento, que ainda está centrada no Norte Global, mas dar a ver os processos que a produziram e que agora a sustentam.

Sob a capa de uma pretensa neutralidade e de uma universalidade imanente, a constituição da Sociologia enquanto disciplina científica se deu lado a lado com discursos legitimadores de certas opções político-econômicoideológicas que, por sua vez, fizeram de uma experiência particular e local de "modernidade" o padrão global inconteste (MIGLIEVICH-RIBEIRO, 2014). É esse o diagnóstico que Connell $(2007 ; 2014)$ estabelece quando defende que a história da Sociologia (ao menos sua versão europeia), desde meados do século XIX até a consolidação dos cânones através de sua assimilação nos EUA, entre 1950 e 1970, deve ser entendida sob o prisma de uma "história global imposta" a partir da Europa. Nesse sentido, uma das maiores implicações das teorias pós e decoloniais foi a de nos alertar para o fato de que, no limite, os "clássicos" da Sociologia - Comte, Marx, Weber, Durkheim, Simmel -, longe de fornecerem observações "neutras" e "universais" sobre as sociedades humanas, na própria construção de suas narrativas e de seus problemas, retrataram sociedades nãoocidentais como essências homogêneas. Para tanto, argumenta Go (2013; 2016), camuflaram a complexidade de suas tensões e as diferenças que as constituiam internamente, transformando-as em um "Outro generalizado" (CONNELL, 1997), em um grande Rest em oposição abissal ao West (HALL, 1995).

Teóricos/as envolvidos/as com os debates pós e decoloniais têm reivindicado uma postura distinta da Sociologia - ou das sociologias - diante da geopolítica global do conhecimento científico, advogando epistemologias alternativas que pautem, de modo reflexivo e público, essa histórica cumplicidade entre o advento da disciplina e os interesses econômicos, políticos e espirituais europeus que formataram uma variedade de colonialidades em todo o Sul Global (ALATAS; SINHA; 2017; BORTOLUCI; JANSEN, 2013; BURAWOY, 2005; COMAROFF; COMAROFF, 2013; CONNELL, 2007; PATEL, 2006; ROSA, 2014; SITAS, 2006; SANTOS, 2019; SANTOS; MENESES, 2009). Alatas (2010), por exemplo, alerta que o eurocentrismo científico não consiste apenas em afirmações flagrantemente racistas ou preconceituosas em relação àquilo que é produzido no Sul Global, fundadas em dicotomias simplistas como avançado-atrasado, desenvolvido-subdesenvolvido, centro-periferia, 
civilizado-primitivo, etc. Em vez disso, elas se traduzem no estatuto marginal e menor de pensadores/as, teorias, metodologias, projetos e conceitos nãoocidentais dentro da Sociologia Global, bem como nas construções problemáticas que decorrem da imposição de categorias "euro-norteamericanas" a campos científicos regionais e locais.

Nesse sentido, o sociólogo malaio propõe "discursos alternativos" e "sociologias endógenas", que se apresentariam sob a forma de nacionalização de disciplinas, indigenização, criatividade intelectual local, descolonização dos saberes e outros deslocamentos que, nos últimos anos, têm indicado os esforços de teorias sociais situadas de transcender elementos metrocêntricos que ainda regulam parte da Sociologia Global (CHAGURI; SILVA, 2018; DÍAZ, 2014; DUFOIS; MACÉ, 2019; MARTINS, 2017; ROSA, 2019; ADESINA, 2002). Esses discursos tratam de aportes informados por experiências históricas regionais, periféricas e semiperiféricas, o que de forma nenhuma as exclui de serem potencialmente universalizadas para outras realidades, situações ou épocas assim como as narrativas do Norte Global também o são, ainda que advogando um saber totalizante, objetivo, abstrato, neutro, descorporificado e auto validador.

Nas décadas 1950 a 1970, as Ciências Sociais latino-americanas viveram um salutar intercâmbio que permitiu a projeção de perspectivas originais, a exemplo do debate sobre a dependência, subdesenvolvimento e capitalismo dependente. As décadas posteriores, contudo, cuidaram de diluir tais esforços. Nos dias de hoje, a irrupção de novas temáticas [...] reivindica consideravelmente novas abordagens epistemológicas; ao mesmo tempo, os países do Sul Global, suas sociedades científicas e intelectuais revigoram-se paulatinamente e criam parcerias que, em alguma medida, autonomizam-se das históricas reverências ao chamado centro. [...] Não é casual que as distintas vertentes [...] cerquem hoje com fôlego renovado a Sociologia [...], relendo eventos históricos e seus discursos legitimadores, quiçá, reescrevendo-os (MIGLIEVICH-RIBEIRO, 2014, p. 75-76),

Para Gregor McLennan (2003), o objetivo da crítica pós e decolonial, quando deslocada para a Sociologia, não é apenas criar um "relato representacional" alternativo, mais fidedigno das "nossas" respectivas histórias nacionais, mas incitar a proliferação de histórias que foram emudecidas. Isso pode ser feito a partir de releituras críticas e pluriversas do passado, escapando 
dos essencialismos etnocêntricos. A essas releituras Mignolo (2010) denominou "gramática da descolonialidade", em que se possibilita, mediante um processo de desconstrução de "grandes narrativas", bem como dos alicerces coloniais e da episteme imperial que as criaram, a abertura de espaços mais democráticos para o aprendizado contínuo, sob os auspícios da pluralidade epistemológica constituinte do mundo. Para tanto, colocam-se os múltiplos vetores de produção científica em correspondência simétrica, a partir de "atitudes" que desestabilizem a violenta arquitetura discursiva da razão científica ocidental - e os epistemicídios que as acompanharam.

A denúncia decolonial, portanto, é justamente a de que o colonialismo, ao lado das formulações intelectuais e disciplinares que o validam até hoje - ainda que em menor grau -, provocaram a exotização, a orientalização, a diferenciação racial e a violência epistêmica como métodos. No cerne do pensamento colonial, encontra-se uma tentativa de classificar, nivelar, submeter e silenciar corpos, histórias, memórias, imaginários e saberes de um suposto "Outro localizado", diferente e distante, hoje simbolizado por muitos países do chamado Sul Global.

O teórico argentino oferece um exame meticuloso sobre local e global na geopolítica do conhecimento, contrapondo à cosmologia hegemônica do Norte situações dialógicas situadas que impliquem a diversidade epistêmica do mundo (MIGNOLO, 2011). Como alternativa à partição "West and Rest", Mignolo trabalha com a linha que traça a própria margem. O conceito fundamental desse arcabouço é "pensamento fronteiriço", que emerge da interseção de histórias locais que efetivam desígnios globais (MIGNOLO, 2003). Essa gnose de fronteira, antes de ser um significante vazio, opera como conector que introduz a diversidade das histórias e teorias locais em um projeto global, desmontando o universalismo abstrato da ciência moderna e dando vazão à "diversalidade como desenho universal". Trata-se de uma "epistemologia pluriversal" para libertar a Teoria Social da tirania do global (MIGNOLO, 2001; 2003; DOMINGUES, 2011).

O conceito de "diversalidade", de Mignolo (2001), foi tomado de uma tradição latino-americana que identificou certa "alienação colonial da consciência”, que deve ser combatida por meio de um deslocamento posicional 
da Teoria Social do continente que, por sua vez, permita reflexões apropriadas de nossa realidade histórica. Alcoff (2017) identifica o poeta da Martinica Edouard Glissant como a grande influência de Mignolo na concepção da ideia de "diversalidade", uma categoria analítica que figura como avesso ao da "universalidade" - geralmente, o universalismo europeu (WALLERSTEIN, 2007). Assim, a "diversalidade" se assemelharia à ideia de pluralidade, em que as alternativas não estariam imbricadas na integração ou interação ativa entre dois diferentes.

A "diversalidade" mapeia as diferenças como co-constitutivas e como potencialmente integradas, na forma como uma identidade bi cultural pode deslocar-se entre múltiplos quadros de referência sem colapsar as diferenças, mas também sem organizá-las em hierarquias. [...] Não é só uma alternativa motivada por razões éticas e políticas à universalidade, [...] mas uma motivação metafísica. É um modelo alternativo de conceptualização da subjetividade e do conhecimento que poderia fazer sentido para a existência de muitos mundos, bem como para tornar visíveis a sua inter-relação e conexão [...] e possibilitar um avanço na adequação descritiva dos horizontes pluritópicos (ALCOFF, 2017, p. 56).

O diagnóstico que a teórica panamenha efetua do conceito de Mignolo, aludindo à uma equalização dos mundos possíveis sem que as diferenças sejam sepultadas, induz à necessidade de fazer visível e inteligível os horizontes pluritópicos do futuro. Para voltar ao terreno sociológico, o convite de Mignolo, endossado por Alcoff, nos leva a repudiar um Sul essencializado, afirmando em vez disso um Sul "plurilocalizado", virtualmente interconectado, ou, segundo a equação de Santos (2018), um Sul Global "pluriverso" e "plurinacional”. Esse Sul - que não é fundamentalmente geográfico, mas conceitual, encontra-se no conjunto de indagações sobre a construção e validação do conhecimento nascido nas tensões entre formas extrativistas e não-extrativistas de vida (Santos, 2019), bem como das "formas de saberes desenvolvidas por agrupamentos e movimentos sociais como parte da sua resistência contra as injustiças e as opressões sistemáticas causadas pelo capitalismo, o colonialismo e o patriarcado" (MENESES, 2018, p. 27). Esses conhecimentos compõem as "epistemologias do sul" (SANTOS, 2018; SANTOS; MENESES, 2009), e ratificam a importância de outros processos de produção de saberes críticos e de novas relações entre diferentes tipos de conhecimentos e práticas de grupos 
subalternizados, vale dizer, grupos que se encontram do outro lado da "linha abissal" (the Rest).

Boaventura de Sousa Santos e Maria Paula Meneses mobilizam o conceito de "ecologia de saberes" a fim de argumentar que o conhecimento científico se legitima na própria relação, de tensão ou complementariedade, que firma entre uma pluralidade de processos epistêmicos, sendo que limites e possibilidades de cada tipo de saber residem na existência de outros saberes e ontologias; logo, só podem ser explorados, valorizados e legitimados na comparação dialógica com formas outras de conhecer e outras histórias ${ }^{8}$, o que nos leva ao "pensamento pós-abissal".

Como ecologia de saberes, o pensamento pós-abissal tem por premissa a ideia da inesgotável diversidade epistemológica do mundo, o reconhecimento da existência de uma pluralidade de formas de conhecimento além do conhecimento científico. Isso implica renunciar a qualquer epistemologia geral. Existem em todo o mundo não só diversas formas de conhecimento da matéria, da sociedade, da vida e do espírito, mas também muitos e diversos conceitos e critérios sobre o que conta como conhecimento. No período de transição que se inicia, em que ainda persistem as perspectivas abissais de totalidade $\mathrm{e}$ unidade, provavelmente precisamos de uma epistemologia geral residual ou negativa para seguir em frente: uma epistemologia geral da impossibilidade de uma epistemologia geral (SANTOS, 2007, p. 85-86).

Esse exercício metodológico de epistemologia política compõe um tipo de "pensamento contrapontual" (GO, 2016; ONG, 1996; SAID, 2011) na Teoria Social, o que põe em xeque espaços autorizados de produção do "saber legítimo", lançando luzes para o fato de que a vida social é constituída de outras geografias de saberes, polifonias e ontologias que incorporam multiplicidades de vozes, histórias, formas de ser e de conhecer. Tais epistemologias residuais asseveram a impossibilidade de uma epistemologia geral9, única e universalista,

\footnotetext{
8 Aliás, Santos (2007) tem proposto uma contra epistemologia para dar consistência a uma sociologia pública, pluralista, progressista e propositiva, respeitadora dos conhecimentos nãocientíficos de grupos subalternizados. O respeito a esses saberes, no registro das "epistemologias do sul" e de uma "ecologia dos saberes", sugere que o saber produzido deve ser tomado como intervenção no real. Segundo Nunes (2008), reconhecer a validade e a legitimidade de outros saberes implica considerar que nenhum conhecimento será desqualificado antes de ter sido posto à prova a sua pertinência em condições situadas. Inversamente, a nenhuma forma de saber deve ser outorgada legitimidade original sem que seja submetida a condições situadas e sem que sejam avaliados seus efeitos sociais.

9 A questão epistemológica clássica é se é possível para qualquer ser humano ter cognição "a respeito do universo além do nicho que ocupa", e também se as pessoas "em nichos diferentes
} 
exigindo que busquemos em nossas práticas, sejam elas disciplinares ou extradisciplinares, o que o sociólogo português chamou de uma "sociologia das ausências" (SANTOS, 2002), cuja intenção é deslocar questões camufladas por trás de suas próprias condições de produção e circulação para o "centro" das disputas culturais, intelectuais e políticas atuais. Isso requer que transformemos as ausências (ou aquilo que foi silenciado, muitas vezes deliberadamente) em presenças constitutivas, isto é, em "emergências". O escopo da "sociologia das ausências" é, portanto, auxiliar agentes sociais historicamente marginalizados a identificar os processos de silenciamento que impediram que suas culturas, experiências, saberes, histórias, estéticas e formas de expressão e resistência se manifestassem, que fossem validadas e reconhecidas, o que atravancou o exercício pleno de suas cidadanias sociais e culturais (SANTOS; NUNES, 2002).

Nesse sentido, acredito que a decolonialidade na Sociologia aparece sob duas formas. Primeiro, em deslocamentos político-epistemológicos e disciplinares que tensionam e desconstroem os intricados processos por meio dos quais a modernidade eurocêntrica firmou o que Boaventura de Sousa Santos (2002) chamou de "conhecimento-regulamentação", que é um padrão científico universalmente exportável (CONNELL, 2007; GO, 2016; SILVA, 2018). Valorizar as epistemologias do sul, as sociologias críticas emergentes e as teorias pós e decoloniais, incluindo aqui as contribuições afro-indígenas, queer e feministas, é estimar saberes erigidos nas lutas (materiais e simbólicas) dos/as excluídos/as da lógica de produção do conhecimento contra injustiças de múltiplas faces. Essa valorização, no entanto, não demanda o rompimento com autores/as só porque são oriundos/as de nações e instituições do Norte Global. Isso consistiria em atitude despropositada e epistemologicamente débil: de um lado, porque ignora o fato de que há correspondências múltiplas e influxos de

podem chegar a compartilhar as mesmas cognições" (SMITH, 2002, p.105). No entanto, Michel Foucault (2005), já no início dos anos 1970, colocou em tensão essa forma clássica de perceber a construção do conhecimento, analisando as correlações possíveis entre saber e poder, afirmando, por conseguinte, que os regimes e os efeitos de verdade são formados por normas sociais que, a depender das intenções subjacentes e das conveniências políticas de agentes e instituições, podem excluir ou, então, incluir discursos e formas de conhecimento. Um debate mais recente tem assinalado que tais questões não se resumem tão somente a uma função normativa da epistemologia - ou seja, verificar como os saberes são produzidos, como a credibilidade é distribuída entre distintos/as agentes -, mas, sobretudo, a sua função política, o que incita a analisar como podem e como devem ser construídos os saberes, quem pode e quem deve ser autorizado a escrever sobre tal e qual assunto, como a credibilidade presuntiva de um enunciado pode e deve ser distribuída socialmente (ALCOFF, 2016; BURAWOY, 2005; FOUCAULT, 1979; SMITH, 2002). 
diferentes vetores na constituição de teorias, como atesta o próprio discurso pós-colonial; de outro, porque tal atitude acaba se convertendo em um tipo invertido de essencialismo epistemológico, que só abre exceção para autores/as e aportes mais diretamente engajados/as com as perspectivas e agências subalternas.

A segunda forma da decolonialidade na Sociologia aparece nos esforços de equalização da balança da geopolítica do conhecimento, no sentido de reconhecer e romper com a reprodução de colonialidades e subalternidades historicamente fundadas. Isso pode abrir espaço para formas alternativas de encarar os problemas do mundo, de vivê-lo, produzi-lo, transformá-lo. Para tanto, é necessário que a disciplina empreenda um diálogo mais simétrico com a pluriculturalidade global, por intermédio de negociações horizontais entre "sulsul" e "sul-norte" (COLLYER et al., 2018; MAIA, 2019) e de maior democratização da produção, difusão e consumo de nossas teorias sociais - que desarticulem o metrocentrismo sociológico (BHAMBHA, 2010; COSTA, 2006a). Isso pode levar as diversas sociologias multi-situadas, sobretudo em contextos periféricos e semiperiféricos, a se encontrarem e se fundamentarem a partir da tensão entre local e global, a se movimentarem e a reinventarem no acúmulo de interconhecimentos específicos e situados; que sejam, através de uma circulação mais autônoma das ideias, incorporadas e multiplicadas umas às outras, levando em conta a variedade de experiências, práticas, histórias, subjetividades, ontologias e emergências epistemológicas do mundo.

Domingues e Bringel (2015) refletiram sobre essa emergência, afirmando que, apesar da convergência de denominadores comuns ligados à produção e difusão assimétrica do saber sociológico e à centralidade do vetor "colonialismo" para o descentramento da disciplina em tradições periféricas - como a brasileira -, a nova gramática de decolonização tem se traduzido em deslocamentos intelectuais heterogêneos do Sul Global. Por isso, para atuar de modo mais pragmático, dentro de uma gama de propostas existentes, é preciso reforçar agendas decoloniais e pós-coloniais, mas ao mesmo tempo vinculá-las à reconfiguração dos processos globais de desenvolvimento, às novas alianças geopolíticas e culturais, às práticas políticas de cooperação "sul-sul" e "nortesul”, à crítica ao metrocentrismo e à emergência de novos sujeitos coletivos. 
Talvez seja o caso de reivindicarmos um saber historicamente contextualizado e guiado por problemas sociológicos situados, mas cuja circulação e alcance consiga impactar realidades as mais heterogêneas possíveis. Nesse cenário de problematização das lógicas da geopolítica do conhecimento, o Sul Global parece se fortalecer quando argumentos e agentes, projetos e intercâmbios, ideias e métodos, processos e histórias apresentados enquanto locais são mobilizados pela Sociologia para desmontar padrões globais dominantes de produção do "saber legítimo", tensionando epistemologias extrativistas e metanarrativas totalizantes.

\section{Referências}

Adams, Julia et al. "Introduction: social theory, modernity, and the three waves of historical Sociology”. In: Remaking Modernity. Durham: Duke University Press, 2005, p. 1-73.

Adesina, Jimi O. Sociology and Yoruba Studies: epistemic intervention or doing sociology in the "vernacular"? African Sociological Review, v. 6, n. 1, p. 91114, 2002.

Alatas, Syed F. A definição e os tipos de discursos alternativos. Revista Estudos Históricos, Rio de Janeiro, v. 23, n. 46, p. 225-245, 2010. . Academic Dependency in the Social Sciences: reflections on India and Malaysia. American Studies International, vol. 38, n. 2, p. 80-96, 2000. . Academic Dependency and the Global Division of Labour in the Social Sciences. Current Sociology, v. 51, n. 6, p. 599-613, 2003. ; Sinha, Vineeta. Sociological Theory Beyond the Cannon. Londres: Palgrave Macmillan, 2017.

Alcoff, Linda Martín. A epistemologia da colonialidade de Mignolo. Epistemologias do Sul, v. 1, n. 1, p. 33-59, 2017. 32, 1991.

. The problem of speaking for others. Cultural Critique, vol. 20, p. 5-

. Uma epistemologia para a próxima revolução. Sociedade \& Estado, v. 31, n. 1, p. 129-143, 2016.

Anzaldúa, Glória. Borderlands: la frontera. São Francisco: Aunt Lute, 1987.

Ashcroft, Bill et al. The empire writes back. London: Routledge, 2002.

Bahri, Deepika. Feminismo e/no pós-colonialismo. Estudos Feministas, v. 21, n. 2, p. 659-688, 2013.

Ballestrin, Luciana. América Latina e o giro decolonial. Revista Brasileira de Ciência Política, n. 11, p. 89-117, 2013. 
. Modernidade/Colonialidade sem "Imperialidade"? O Elo Perdido do Giro Decolonial. Dados, vol. 6o, n. 2, p. 505-540, 2017.

Bhabha, Homi. O Local da Cultura. Belo Horizonte: Editora UFMG, 2001. Bhambra, Gurminder. Connected Sociologies. London: Bloomsbury, 2014.

. Rethinking Modernity. New York: Palgrave Macmillan, 2007.

. Sociology After Postcolonialism. In: Gutiérrez-Rodriguez, Encarnación;

Boatcâ, Manuela; Costa, Sérgio. Decolonizing European Sociology:

Transdisciplinary Approaches. Burlington/Surrey: Ashgate, 2010, p. 3347.

Bortoluci, José Henrique; Jansen, Robert S. Toward a Postcolonial Sociology: The View from Latin America. Political Power and Social Theory, vol. 24, p. 199- 229, 2013.

Bringel, Breno; Domingues, José Maurício. Teoria social, extroversão e autonomia: impasses e horizontes da sociologia (semi)periférica contemporânea. Cadernos CRH, vol. 28, n. 73, 2015, p. 59-76.

Burawoy, Michael. For public sociology. American Sociological Review, vol. 70, p. 4-28, 2005.

Carneiro, Sueli. Do Epistemicídio. In: A construção do outro como não-ser como fundamento do ser. Tese de Doutorado, Faculdade de Educação, USP, São Paulo, 2005, p. 96-124.

Castro-Gómez, Santiago. ¿Qué hacer con los universalismos occidentales? Observaciones en torno al "giro decolonial". Analecta Política, v. 7, n. 13, p. 249-272, 2017.

; Grosfoguel, Ramón (Orgs.) El giro decolonial: reflexiones para una diversidad epistémica más allá del capitalismo global. Bogotá: Siglo del Hombre Editores, 2007.

Chakrabarty, Dipesh. Provincializing Europe: Postcolonial thought and historical difference. Princeton: Princeton University Press, 2000a.

. Subaltern Studies and Postcolonial Historiography. Nepantla: Views from South, vol. 1, n. 1, p. 9-32, 200ob.

Chatuverdi, Vinayak. Mapping Subaltern Studies and the Postcolonial. London: Verso, 2000.

Collyer, Fran; Connell, Raewyn; Maia, João Marcelo; Morrell, Robert.

Knowledge and Global Power: making new sciences in the South. Clayton: Monash University Publishing, 2018.

Comaroff, Jean; Comaroff, John. Teoría desde el sur. Buenos Aires: Siglo

Veintiuno, 2013.

Connell, Raewyn. Rethinking Gender from the South. Feminist Studies, vol. 40, n. 3, p. 518-539, 2014.

. Social Science on a world scale: connecting the pages. Sociologies in Dialogue, Porto Alegre, v. 1, n. 1, p. 1-16, 2015.

. Southern Theory. Sydney: Allen \& Unwin, 2007. 
Why is classical theory classical. American Journal of Sociology,

vol. 102, n. 6, p. 1511-1557, 1997.

; Collyer, Fran; Maia, João; Morrell, Robert. Knowledge and Global

Power: making new sciences in the South. Clayton: Monash University

Publishing, 2018.

Costa, Sérgio. Desprovincializando a sociologia. RBCS, vol. 21, n. 60, p. 117-134, 2006a.

Dois atlânticos: teoria social, antirracismo, cosmopolitismo. Belo Horizonte: Editora UFMG, 2006b.

Díaz, Mónica. El "nuevo paradigma" de los estudios coloniales latinoamericanos: un cuarto de siglo después. Revista de Estudios Hispánicos, vol. 48, n. 3, p. 519-547, 2014.

Dirlik, Arif. Global modernity? Modernity in an age of global capitalism. European Journal of Social Theory, vol. 6, n. 3, p. 275-292, 2003.

. The Aura of Postcolonialism: Third-World Criticism in the Age of Global Capitalism. In: Mongia, Padmini. Contemporary Postcolonial Theory: A Reader. London: Arnold, 1996, p. 294-320.

Domingues, José Maurício. Teoria Crítica e Semi(Periferia). Belo Horizonte: Ed.UFMG, 2011.

Dufoix, Stéphane; Macé, Éric. Les enjeux d'une sociologie mondiale nonhégémonique. Zilsel, vol. 5, n. 1, p. 88-121, 2019.

Dussel, Enrique. Europa, Modernidade e Eurocentrismo. In. Lander, Edgardo (Org.) Colonialidade do saber. Buenos Aires: CLACSO, 2005, p. 55-70. 2002.

World-System and Transmodernity. Nepantla, vol. 3, n. 2, p. 221-244,

Eisenstadt, Shmuel. Multiple Modernities. New Brunswick/London: Transaction, 2002.

Foucault, Michel. Microfísica do poder. Rio de Janeiro: Graal, 1979.

Gandhi, Leela. Postcolonial Theory. New York: Columbia University Press, 1998.

Gaonkar, Dilip. On Alternative Modernities. Public Culture, vol. 11, n. 1, p. 118, 1999.

Go, Julian. For a postcolonial sociology. Theory and Society, vol. 42, n. 1, p. 25-55, 2013.

Postcolonial Thought and Social Theory. New York: Oxford University Press, 2016.

Grosfoguel, Ramón. Colonial Difference, Geopolitics of Knowledge, and Global Coloniality in the Modern/Colonial Capitalist World-System. Review:

Fernand Braudel Center, vol. 25, n. 3, p. 203-224, 2002.

. Descolonizando los universalismos occidentales. In: Castro-Gómez, Santiago; Grosfoguel, Ramon (Orgs.) El giro decolonial. Bogotá: Siglo del Hombre Editores, 2007a, p. 63-79. 
Dilemas dos estudos étnicos norte-americanos: multiculturalismo identitário, colonização disciplinar e epistemologias descoloniais. Ciência \& Cultura, vol. 59, n. 2, p. 32-35, 2007b.

Guha, Ranajit. Las voces de la historia y otros estudios subalternos. Barcelona: Crítica, 2002.

Habermas, Jürgen. Modernidade: projeto inacabado. In: Arantes, Otília; Arantes, Paulo. Um ponto cego no projeto moderno de Jürgen Habermas. São Paulo: Brasiliense, 1992, p. 99-124.

Hall, Stuart. The West and the Rest: Discourse and Power. In: Hall, Stuart; Gieben, Bram (Orgs.) Formations of Modernity. Cambrigde: Blackwell, 1995, p. 276-333.

When Was "the Post-colonial"? Thinking at the Limit. In: Chambers, Iain; Curti, Lidia (Orgs.) The Post-colonial Question: Common Skies, Divided Horizons. London: Routledge, 1996, p. 242-260.

Hanafi, Sari. Global sociology revisited toward new directions. Current Sociology, vol. 68, n. 1, p. 3-21, 2020.

hooks, bell. From margin to center. Boston: South End Press, 1984. Hostettler, Nicholas A critical theory of Eurocentrism. PhD Thesis. SOAS, University of London, 2008.

Keim, Wiebke. Social sciences internationally: the problem of marginalisation and its consequences for the discipline of sociology. African Sociological Review, vol. 12, n. 12, p. 22-48, 2008.

Kempel, Thomas; Mawani, Renisa. The Sociological Imagination and its Imperial Shadows. Theory, Culture, and Society, vol. 26, n. 7-8, p. 340-55, 2009.

Lander, Edgardo (Org.) A colonialidade do saber: eurocentrismo e ciências sociais. Perspectivas latino-americanas. Buenos Aires: CLACSO, 2005.

Latin American Subaltern Studies Group. Founding Statement. Boundary 2 , vol. 20, n. 3, p. 110-121, 1993.

Lugones, María. Rumo a um feminismo descolonial. Estudos Feministas, v. 22, n. 3, p. 935-952, 2014.

Maia, João Marcelo E. Ciências Sociais, Trabalho Intelectual e Autonomia: Quatro Estudos de Caso sobre Nós Mesmos. Dados - Revista de Ciências Sociais, v. 62, p. 1-33, 2019.

Maldonado-Torres, Nelson. A topologia do ser e a geopolítica do conhecimento. Revista Crítica de Ciências Sociais, n. 80, p. 71-114, 2008.

. Sobre la colonialidad del ser. In: Castro-Gómez, Santiago; Grosfoguel, Ramon (Orgs.) El giro decolonial. Bogotá: Siglo del Hombre Editores, 2007, p. 127-167.

. Thinking through the Decolonial Turn: Post-continental Interventions

in Theory, Philosophy, and Critique: an introduction. Transmodernity, vol. 1, n. 2, p. 1-15, 2011. 
Mariátegui, José Carlos. Sete ensaios de interpretação da realidade latino-americana. São Paulo: Expressão Popular, 2010.

Martins, Paulo Henrique. Norte e Sul como Referências para uma Ciência Social global: Transdisciplinar, Antiutilitarista e Pós-Colonial. Revista TOMO, n. 31, p. 41-89, 2017.

Medina, Leandro Rodriguez. Centers and Peripheries in Knowledge Production. New York/London: Routledge, 2013.

Meneses, Maria Paula. Apresentação: Pensando desde o Sul e com o Sul. In: Santos, Boaventura de Sousa. Construindo as Epistemologias do Sul. Buenos Aires: CLACSO, 2018, p. 23-30.

Os sentidos da descolonização: uma análise a partir de Moçambique.

Revista OPSIS, vol. 16, n. 1, p. 26-44, 2016.

McLennan, Gregor. Sociology, Eurocentrism and Postcolonial Theory. European Journal of Social Theory, vol. 6, n. 1, p. 69-86, 2003.

Miglievich-Ribeiro, Adelia Maria. Por uma razão decolonial: desafios éticopolítico-epistemológicos à cosmovisão moderna. Civitas, v. 14, p. 66-80, 2014.

; Prazeres, Lílian Lima Gonçalves dos. A produção da subalternidade sob a ótica pós-colonial (e decolonial): algumas leituras. Temáticas, vol. 23, n. 45/46, p. 25-52, 2015.

Mignolo, Walter. Colonial and Postcolonial Discourse: Cultural Critique or Academic Colonialism? Latin American Research Review, vol. 28, n. 3, p. 120-134, 1993.

. Coloniality of Power and Subalternity. Rodriguez, Iliana (Org.) The Latin Amerian Sublatern Studies Reader. Durham: Duke University Press, 2001, p. 424-244.

Desobediencia epistémica: retórica de la modernidad, lógica de la colonialidad y gramática de la descolonialidad. Buenos Aires: Del Signo, 2010.

Historias locales/diseños globales. Madrid: Akal, 2003.

Os esplendores e as misérias da "ciência". In: Santos, Boaventura de Sousa (Org.) Conhecimento prudente para uma vida decente. São Paulo: Cortez, 2006, p. 667-710.

Press, 2011.

The darker side of western modernity. Durham: Duke University

Nunes, João Arriscado. O resgate da epistemologia. Revista Crítica de Ciências Sociais, n. 80, p. 45-7, 2008.

Oliveira, Lucas Amaral de. Experiências Estéticas em Movimento: Produção Literária nas Periferias Paulistanas. Tese (Doutorado em Sociologia), USP, São Paulo, 2018.

2020.

Por uma Sociologia do Encontro. Mediações, vol. 25, n. 1, p. 142-160, 
Ong, Aihwa. Anthropology, China and Modernities: The Geopolitics of Cultural Knowledge. In: Moore, Henrietta (Org.) The Future of Anthropological Knowledge. New York: Routledge, 1996, p. 60-92.

Patel, Sujata. Afterword: doing global sociology: issues problems and challenges. Current Sociology, vol. 62, n. 4, p. 603-613, 2014.

. Beyond binaries: a case for self-reflexive sociologies. Current

Sociology, vol. 54, n. 3, p. 381-395, 2006.

Quijano, Aníbal. Colonialidad y modernidad/racionalidade. Perú Indígena, vol. 13, n. 29, p. 11-20, 1992.

. Colonialidade do poder e classificação social. In: Santos, Boaventura de Sousa; Meneses, Maria Paula (Orgs.) Epistemologias do Sul. Coimbra: Almedina, 2009, p. 73-116.

Cuestiones y horizontes: de la dependencia histórico-estructural a la colonialidad/descolonialidad del poder. Buenos Aires: CLACSO, 2014.

. La nueva heterogeneidad estructural de América Latina. In: Sonntag, Heinz Rudolf (Org.) ¿Nuevos Temas, Nuevos Contenidos? Caracas: Nueva Sociedad, 1989, p. 29-51.

Randeria, Shalini. Entangled Modernities: Postcolonial Perspectives on Europe. Decentering Europe. Lecture. 25 Octubre, 2010.

Rosa, Marcelo. A África, o Sul e as ciências sociais brasileiras: descolonização e abertura. Sociedade \& Estado, v. 30, n. 2, p. 313-321, 2015.

Sociologias do Sul: ensaio bibliográfico sobre limites e perspectivas de um campo emergente. Civitas, v. 14, n. 1, p. 43-65, 2014.

Rubbo, Deni. O labirinto periférico: José Carlos Mariátegui e a sociologia crítica latino-americana. 2018. Tese (Doutorado em Sociologia), USP, São Paulo, 2018.

Said, Edward. Cultura e Imperialismo. São Paulo: Shwarcz, 2011.

. Orientalismo. São Paulo: Cia das Letras, 1990.

Santos, Boaventura de Sousa. Introdução às Epistemologias do Sul. In:

Construindo as Epistemologias do Sul. Buenos Aires: CLACSO, 2018, p. 297-335.

. O fim do império cognitivo: a afirmação das Epistemologias do Sul. Belo Horizonte: Autêntica, 2019.

. Para além do pensamento abissal: das linhas globais a uma ecologia de saberes. Novos Estudos CEBRAP, n. 79, p. 71-94, 2007.

. Para uma sociologia das ausências e uma sociologia das emergências.

Revista Crítica de Ciências Sociais, n. 63, p. 237-280, 2002.

Pela mão de Alice: o social e o político na pós-modernidade. Porto:

Edições Afrontamento, 1994.

; Meneses, Maria Paula. Epistemologias do Sul. Coimbra: Almedina, 2009. 
; Nunes, João Arriscado. Para ampliar o cânon do reconhecimento, da diferença e da igualdade. In: Santos, Boaventura de Sousa (Org.) Reconhecer para Libertar. Rio de Janeiro: Record, 2002, p. 25-68.

Sarlo, Beatriz. Modernidades periféricas. São Paulo: CosacNaify, 2010.

Schmidt, Volker. Multiple Modernities or Varieties of Modernity? Current Sociology, vol. 54, n. 1, p. 77-97, 2006.

Segato, Rita Laura. La crítica de la colonialidad en ocho ensayos. Buenos Aires: Prometeo, 2018, p. 35-67.

Silva, Josué Pereira da. Epistemologia do Sul como Teoria Crítica? Nota crítica sobre a teoria da emancipação de Boaventura de Sousa Santos. In: Chaguri, Mariana, Silva, Mario Augusto Medeiros da. (Orgs.) Rumos do sul: periferia e pensamento social. São Paulo: Alameda, 2018, p. 89-108.

Sitas, Ari. The African renaissance challenge and sociological reclamations in the south. Current Sociology, vol. 54, n. 3, p. 357-380, 2006.

Smith, Barbara Herrnstein. Crença e Resistência: a dinâmica da controvérsia intelectual contemporânea. São Paulo: Editora da Unesp, 2002.

Souza, Jessé. A modernização seletiva. Brasília: Editora UnB, 2000.

Spivak, Gayatri. Can the subaltern speak? In: Nelson, Cary; Grossberg, Lawrence (Orgs.) Marxism and the Interpretation of Culture. Chicago: University of Illinois Press, 1988, p. 271-313.

Steinmetz, George (Org.) Sociology and Empire. Durham: Duke University Press, 2013.

Therborn, Göran. Entangled Modernities. European Journal of Social Theory, vol. 6, n. 3, p. 293-305, 2003.

Verdesio, Gustavo. Introduction: Latin American Subaltern Studies: is there life after the demise of the group? Dispositio, vol. 25, n. 52, p. 5-42, 2005.

Wallerstein, Immanuel. O universalismo europeu. São Paulo: Boitempo, 2007.

Walsh, Catherine. Interculturalidade crítica e pedagogia decolonial. In: Candau, Vera M. (Org.) Educação intercultural na América Latina. Rio de Janeiro: 7Letras, 2009, p. 12-43.

Wittrock, Björn. Modernity: One, None, or Many? European Origins and Modernity as a Global Condition. Daedalus, vol. 129, n. 1, p. 31-6o, 2000.

Young, Robert. Postcolonialism: an historical introduction. Malden: Blackwell, 2001. 